\title{
Comparison between ultrasonographic findings and fine needle aspiration cytology in differentiating malignant and benign thyroid nodules
}

\author{
Mahdi Mohebbi (1), Mehrzad Gholampour Dehaki (1), Mahsa Mozaffari (2) \\ (1) Department of Internal Medicine, School of Medicine, Aja University of Medical Sciences, \\ Tehran, Iran; (2) Department of Pediatrics, Iran University of Medical Sciences, Tehran, Iran \\ This article is distributed under the terms of the Creative Commons Attribution Noncommercial License (CC BY-NC 4.0) which permits \\ any noncommercial use, distribution, and reproduction in any medium, provided the original author(s) and source are credited.
}

\begin{abstract}
The purpose of research was comparing the ultrasound (US) features and fine-needle aspiration cytology (FNAC) in detecting the thyroid nodules in clinical practice. A cross-sectional analytical study retrospectively reviewed the US and FNAC findings for a total of 170 thyroid nodules. The US features that we compared included echogenicity, calcifications, shape, halo and Doppler, between 2017 and 2018. Totally, 170 nodules of thyroid were studied, which contained $72(42.4 \%)$ benign and $98(57.6 \%)$ malignant thyroid nodules. The sonographic features were significantly associated with malignancy such as microcalcification (97.0\%), hyperechogenicity $(91.5 \%)$, wider than taller shape $(98.0 \%)$, absent halo $(90.9 \%)$ and positive Doppler $(78.0 \%)(\mathrm{P}<0.01)$. The altogether accuracies of calcification, echogenicity, shape, halo, and Doppler were 0.96, 0.92, 0.97,0.82 and 0.82, respectively. Our data suggest that US features could be a good sonographic criterion for recommending FNA cytology with follow-up thyroid sonography and FNA.
\end{abstract}

Key Words: ultrasound, fine-needle aspiration, thyroid, clinical.

Eur J Transl Myol 29 (3): 261-267, 2019

In recent years, fine-needle aspiration cytology (FNAC) has became the gold standard diagnostic procedure for therapy plans for euthyroid patients with thyroid parenchymal nodules. ${ }^{1-5}$ FNAC reduces significantly the number of dispensable surgeries of thyroid (thyroidectomy) for patients with benign nodules, because FNAC is growing in detection of malignancy potentials of thyroid nodules. ${ }^{1-8}$ The Bethesda System of Reporting Thyroid Cytopathology (TBSRTC) is launched in 2007 by the National Cancer Institute (NCI) that describes uniform terminology and diagnostic criteria for thyroid FNA specimens to communicating with pathologists and clinicians. Of course, in December 2010, the ultimate version of TBSRTC was institutionalized with the publication. TBSRTC categorizes the cytological data in 6 classes composed of nondiagnostic or unsatisfactory (ND/UNS, Bethesda I); benign (Bethesda II); atypia of undetermined significance (AUS, Bethesda III) or follicular lesion of undetermined significance (FLUS, Bethesda III); follicular neoplasm (FN, Bethesda IV) or suspicious for FN; suspicious for malignancy (SM, Bethesda V); and malignant (Bethesda VI). ${ }^{9-13}$ Thyroid ultrasound (US) is an extensive tool that is utilized as a first-line diagnostic procedure in thyroid nodules (TNs) and it plays a fundamental role in finding malignant TNs leading to a better prognosis and in selecting TNs for FNA. As compared with FNA, ultrasonography of thyroid has the benefit of a non-invasive nature and is a method with giving quick data. In fact, FNAC is appraised as a procedure of selecting to diagnose TNs, but it is invasive. Afterward, it can be refrained in nodules without suspicious specifications to a less invasive test. Taken together, the main dispute is over the precise recognition malignant TNs and to abstain from unessential methods for benign nodules. ${ }^{14-22}$ Therefore, in the current study, we investigated the comparison of results from US features and FNAC on thyroid nodules in clinical practice.

\section{Materials and Methods}

\section{Study population}

A study with retrospective cross-sectional was conducted at the Research Institute for Cancer diseases, as the main referral center for Cancer patients in Tehran, Iran.

The records of patients referred to the clinic and patients are selected to allow the results of their cytology and 
Table1. Characteristics of the thyroid nodules

\begin{tabular}{|c|c|c|}
\hline Variables & $\begin{array}{c}\text { Frequency } \\
(\text { Total=170) }\end{array}$ & Percent \\
\hline \multicolumn{3}{|l|}{ Calcification } \\
\hline Eggshell & 17 & 10.0 \\
\hline Coarse & 17 & 10.0 \\
\hline Absent & 54 & 31.8 \\
\hline Macro & 16 & 9.4 \\
\hline Micro & 66 & 38.8 \\
\hline \multicolumn{3}{|l|}{ Echogenicity } \\
\hline Hyper & 13 & 7.6 \\
\hline Нypo & 106 & 62.4 \\
\hline Isoechoic & 51 & 30.0 \\
\hline \multicolumn{3}{|l|}{ Shape } \\
\hline Ovoid to round & 5 & 2.9 \\
\hline Taller than wider & 99 & 58.2 \\
\hline Wider than taller & 66 & 38.8 \\
\hline \multicolumn{3}{|l|}{ Halo } \\
\hline Thin & 47 & 27.6 \\
\hline Incompletely thin & 46 & 27.1 \\
\hline Absent & 77 & 45.3 \\
\hline \multicolumn{3}{|l|}{ Doppler central flow } \\
\hline Negative & 43 & 25.3 \\
\hline Positive & 127 & 74.7 \\
\hline
\end{tabular}

sonography to be available and then their demographic and epidemiological characteristics presented and the diagnostic methods mentioned are compared. Pathological slides and cytology samples and their sonographic findings will be reviewed as well as the number of all patients enrolled in the study will be randomized sampling. Among 170 suspected patients of thyroid cancer, 98 subjects have positive tests results after Pathology and were considered as case and noncancer patients considered as controls. We use the Bethesda System for Reporting Thyroid Cytopathology (TBSRTC), in which (Bethesda initial version in 2009 and the second edition in 2017), there are six main diagnostic groups: ${ }^{23}$

1. Non-diagnostic or unsatisfactory

2. Benign

3. Atypia of undetermined significance (AUS) or follicular lesion of undetermined significance (FLUS)
4. Follicular neoplasm or suspicious for a follicular neoplasm (FN/SFN)

5. Suspicious for malignancy

6. Malignant

\section{Statistical analysis}

In this study, ordinal regression (ordinal classification) analysis was employed to assess the relation between ultrasound (US) features and fine-needle aspiration cytology (FNAC) and to report odds ratio (OR) and 95\% confidence interval (CI). The sensitivity, specificity and predictive values of ultrasound (US) features against (FNAC) were counted by receiver operator characteristics (ROC) analysis and the area under the curve (AUC). To display small variables from the mean $\pm \mathrm{SD}$, we will use frequency to display qualitative variables. Significance level is less than 0.05. Statistical analyses were done by using IBM SPSS Statistics for Windows, Version 25.0. 
Thyroid nodules

Eur J Transl Myol 29 (3): 261-267, 2019

Table2. Relationship between ultrasound features and fine needle aspiration results

\begin{tabular}{|c|c|c|c|c|}
\hline Sonographic features & Benign [n (\%)] & Malignant [n (\%)] & $\begin{array}{c}\text { Odds Ratio (95\% confidence } \\
\text { interval) }\end{array}$ & $\mathrm{p}$ value \\
\hline \multicolumn{5}{|l|}{ Calcification } \\
\hline Absent & $50(92.6 \%)$ & $4(7.4 \%)$ & $0.013(0.005,0.038)$ & $<0.001$ \\
\hline Eggshell & $17(100.0 \%)$ & $0(0.0 \%)$ & $0.061(0.028,0.133)$ & $<0.001$ \\
\hline Macro & $0(0.0 \%)$ & $16(100.0 \%)$ & $0.257(0159,0.415)$ & $<0.001$ \\
\hline Coarse & $0(0.0 \%)$ & $17(100.0 \%)$ & $0.566(0.376,0.852)$ & 0.006 \\
\hline Micro & $2(3.0 \%)$ & $64(97.0 \%)$ & - & - \\
\hline \multicolumn{5}{|l|}{ Echogenicity } \\
\hline Isoechoic & $13(100.0 \%)$ & $0(0.0 \%)$ & $0.018(0.005,0.053)$ & $<0.001$ \\
\hline Нуро & $9(8.5 \%)$ & $97(91.5 \%)$ & $0.042(0.016,0.113)$ & $<0.001$ \\
\hline Hyper & $47(92.2 \%)$ & $4(7.8 \%)$ & & - \\
\hline \multicolumn{5}{|l|}{ Shape } \\
\hline Ovoid to round & $4(80.0 \%)$ & $1(20.0 \%)$ & $0.0001(0.00002,0.0008)$ & $<0.001$ \\
\hline Taller than wider & $2(2.0 \%)$ & $97(98.0 \%)$ & $0.042(0.015,0.113)$ & $<0.001$ \\
\hline Wider than taller & $63(95.5 \%)$ & $3(4.5 \%)$ & - & - \\
\hline \multicolumn{5}{|l|}{ Halo } \\
\hline Thin & $43(91.5 \%)$ & $4(8.5 \%)$ & $0.059(0.030,0.116)$ & $<0.001$ \\
\hline Incompletely thin & $19(41.3 \%)$ & $27(58.7 \%)$ & $0.432(0.283,0.659)$ & $<0.001$ \\
\hline Absent & $7(9.1 \%)$ & $70(90.9 \%)$ & & \\
\hline \multicolumn{5}{|l|}{ Doppler central flow } \\
\hline Negative & $41(95.3 \%)$ & $2(4.7 \%)$ & $0.019(0.004,0.085)$ & $<0.001$ \\
\hline Positive & $28(22.0 \%)$ & $99(78.0 \%)$ & - & - \\
\hline
\end{tabular}

\section{Results}

In this study, we found that men percent in the malignant group $(75.6 \%)$ are significantly higher than women $(51.9 \%)$. The mean \pm SD age in the malignant group was $61.63 \pm 6.80$ and in the benign group was $54.92 \pm 10.75$. The frequency and percentage of ultrasound (US) features are reported in Table 1. Table 2 shows the relation between ultrasound (US) features and fine- needle aspiration cytology (FNAC) results. Significant positive relations were found between all US and FNAC results. For features of calcification; Absent, Eggshell, Macro, Coarse against of Micro we found respectively (OR 0.013, CI 0.005- 0.038), (OR 0.061, CI 0.0280.133), (OR 0.257, CI 0159- 0.415) and, (OR 0.566, CI $0.376,0.852)$. For features of Echogenicity; Isoechoic and Hyper against of Hypo, respectively we got (OR 0.018, CI 0.005-0.053) and (OR 0.042, CI 0.016-0.113).

Table 3. Sensitivity and specificity of thyroid nodules diagnostic tests

\begin{tabular}{cccccc}
\hline $\begin{array}{c}\text { Ultrasound } \\
\text { features' } \\
\text { characteristics }\end{array}$ & sensitivity & specificity & $\begin{array}{c}\text { Positive predictive } \\
\text { value }\end{array}$ & $\begin{array}{c}\text { Negative predictive } \\
\text { value }\end{array}$ & Accuracy \\
\hline Calcification & 0.960 & 0.71 & 0.94 & 0.98 & 0.96 \\
Echogenicity & 0.960 & 0.87 & 0.94 & 0.91 & 0.92 \\
Shape & 0.960 & 0.71 & 0.94 & 0.98 & 0.97 \\
Halo & 0.960 & 0.62 & 0.91 & 0.79 & 0.82 \\
Doppler & 0.980 & 0.59 & 0.95 & 0.78 & 0.82 \\
\hline
\end{tabular}




\section{Thyroid nodules}

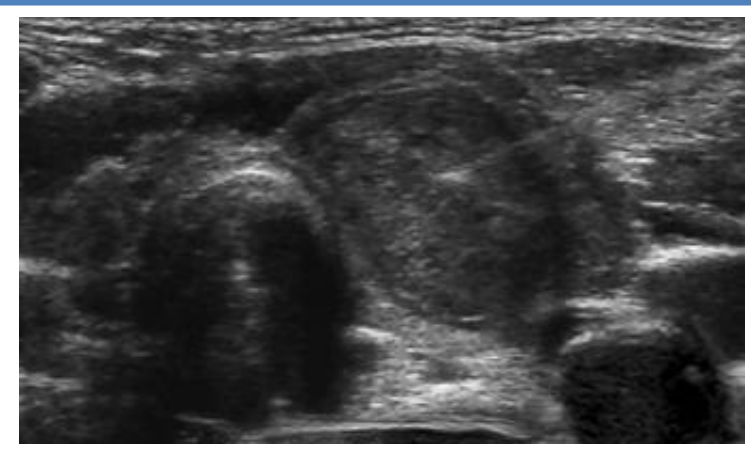

Fig 1. Fine needle aspiration guided by sonography of a hypoechoic nodule proved as papillary thyroid carcinoma.

Ovoid to round and Wider than taller against of Taller than wider we were (OR 0.0001, CI 0.00002-0.0008) and (OR 0.042, CI 0.015- 0.113), For features of Halo; thin and Incompletely thin against of Absent, we got respectively (OR 0.059, CI 0.030-0.116) and (OR 0.432, CI 0.283- 0.659) and for features of Doppler central flow; negative against of positive we received at (OR 0.019, CI 0.004-0.085). Table 3 suggests the calculated sensitivity, specificity, predictive vales and accuracy of thyroid nodules by ultrasound features. Figure 1 shows the ROC curve for the sensitivity and specificity of US, shape had the greatest predictive ability $(\mathrm{AUC}=0.962)$, and then

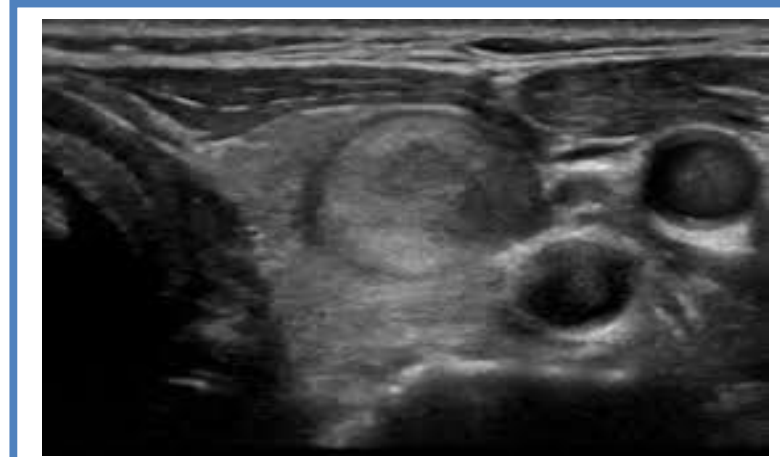

Fig 2. Ultrasound features shown in the figure of hypoechoic thyroid nodules proved as papillary carcinoma by cytology

respectively calcification $(\mathrm{AUC}=0.956)$, echogenicity $(\mathrm{AUC}=0.911)$, halo $(\mathrm{AUC}=0.871)$ and, Doppler central flow $(\mathrm{AUC}=0.787)$. Figure 2 and 3 indicate the thyroid nodules ultrasound characteristics' and the process of which the nodules are gone under aspiration by the fine needle.

\section{Discussion}

In this study, the prevalence of malignancy in men was $75.6 \%$ and in women was $51.9 \%$, but comparing to other studies this difference was significant. But, Razmpa et al., 2002 reported the incidence of malignancy in men

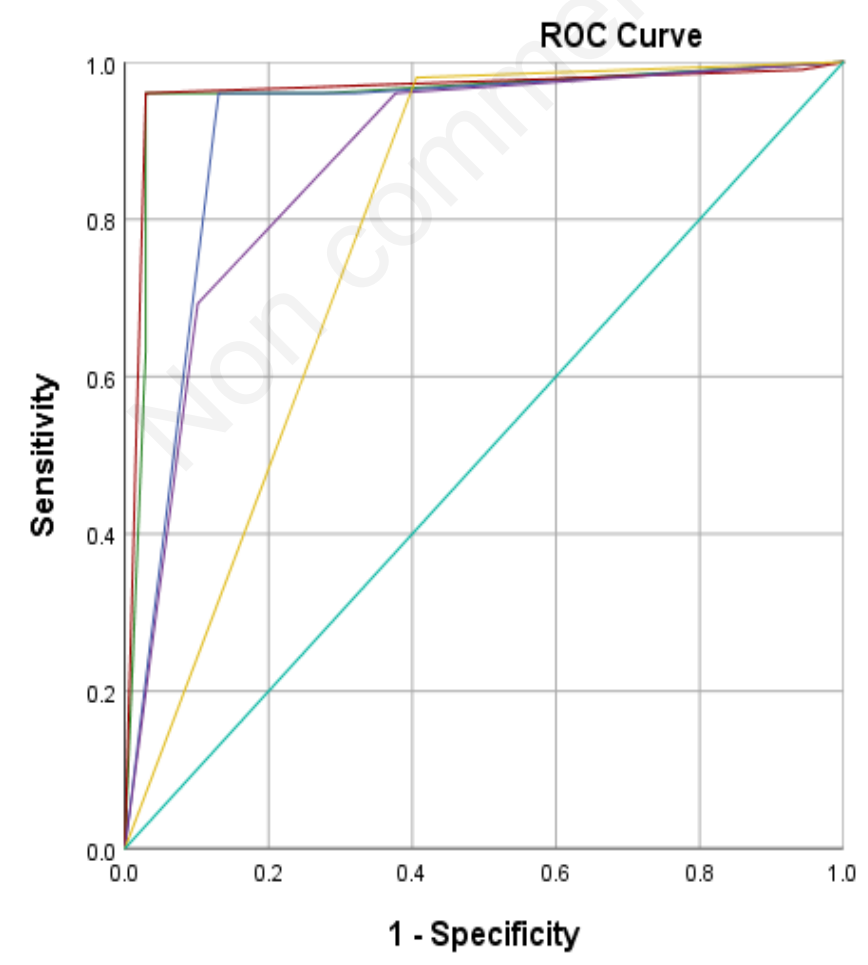

\section{Source of the Curve}

- sonography.calcification

- echogenicity

- shape

halo

dopler.cental.flow

- Reference Line

Fig 3. Receiver operating characteristic curve estimates the ability of ultrasound to diagnose malignant nodules 
was $76 \%$ and in women was $71 \%$, which shows this difference was no significant, ${ }^{20}$ in contrast with present research. However, it may be due to the average patients' age who had malignant nodules was notably higher than people with benign nodules such as findings from Lin et al.,1997 and Danese et al.,1998. ${ }^{21,22}$ On the other hand, the malignant portion of thyroid nodules was $57.6 \%$, which is seemingly higher than in most previous reports from Nam-Goong et al., 2004, Izquierdo et al., 2006, and Frates et al., 2006, which might result from selection bias based on sonographic findings of the people who had undergone surgery. ${ }^{23-25}$ In parallel, Ishida et al.,1988 suggested that $0.14 \%$ of the general Japanese population had malignant thyroid nodules. ${ }^{26}$ a range that is lower than our report. Moreover, Park et al., 2011 reported that the malignancy rate for the nodules identified as benign was $2.8 \%$, and $68.7 \%$ for nodules suspicious for malignancy. ${ }^{27}$ In the present study, hypoechogenicity as one of sonographic characteristics was the most worth measure to predict malignancy $(91.5 \%)$, with $0.96 \%$ sensitivity, $87 \%$ specificity and $92 \%$ accuracy. Other studies by Nabahati et al., ${ }^{14}$ and Alam et al., ${ }^{28}$ have reported that hypoechogenicity was most anticipated scale for malignancy, these rates were observed, (53\% sensitivity, $77 \%$ specificity), (42\% sensitivity and $75 \%$ specificity), respectively, which were in contrast to our data. Furthermore, in conflict with our results, in another study by Sankhla et al., 2001, found 33\% of hypoechoic malignant nodules and $11 \%$ of hyperechoic malignant nodules. ${ }^{29}$ Calcifications are seen in both malignant nodules and benign ones. According to our results, calcification was related to low specificity $(0.71 \%)$, but high sensitivity $(0.96 \%)$, which was in contrast with the previously published data like, Alam et al., 2014, Kim et al., 2002, Papini et al., 2002 and Nabahati et al., 2019. ${ }^{14,28,30,31}$ Of course, some studies are in agreement with our results, which showed a higher rate of sensitivity such as $\mathrm{Xu}$ et al.,2017, ${ }^{32}$ moreover, microcalcification was associated with malignancy $(97.0 \%)$ and benign (3.0\%), but there were conflicting data about absent, eggshell, coarse, and macrocalcification such as studies published from Petrone et al., 2012, Kim et al., 2013, and Park et al., 2014. ${ }^{33-35}$ A study by Koike et al., 2001, ${ }^{36}$ indicated that calcification had a sensitivity of $88.7 \%$ and Ram et al., 2015 showed a high sensitivity $(80 \%)$ and a relatively lower specificity $(68 \%)$ for calcification, ${ }^{19}$ results of these two studies are relatively close to our findings for calcification (both micro as well as macro). On the other hand, our data have clearly demonstrated that taller than wider shape was the other predicting feature of malignancy with high sensitivity but low specificity. These results were in contrast with Kwak et al., 2011, Ram et al., 2015, and Wang et al., 2017, and also, consistent with, Ren et al., 2015, Nabahati et al., 2019 and Moon et al, 2011, who demonstrated a tallerthan-wide shape can be of a good help in predicting malignant nodules. ${ }^{19,37-40}$ Our results revealed that difference between isoechoic nodules $(0.0 \%)$, hypoechoic nodules $(91.5 \%)$ and hyperchoic nodules $(7.8 \%)$, was statistically significant, the research by Degirmenci et al., ${ }^{41}$ reported the hypoechoic nodules (35.9\%), isoechoic nodule $(28.6 \%)$ or hyperechoic nodules $(33.3 \%)$ were no different in number. The study by Leenhardt et al., ${ }^{42}$ showed the hypoechoic and isoechoic nodules (20\% and $21 \%$, respectively) compared with hyperechoic nodules $(7 \%)$. Our data showed relatively higher rates of nondiagnostic cytology and one feasible statement is nodules with hypoechogenecity are associated with more fibrosis that might lead to a higher contingency of nondiagnostic report of cytology. In conclusion, our data suggest that US features like microcalcification, hypoechogenicity, taller than wider shape, and absent halo could be a good sonographic criterion for recommending FNA cytology, the US as useful approach might help to facilitate the diagnosis in patients with thyroid nodules, and finally, it can be proposed that the FNA utilize on planning of surgery for thyroid nodules and especially for follow-up of the patients. However, further studies containing a greater study population are necessary to confirm our study findings.

\section{List of acronyms}

AUS - Atypia of undetermined significance interval

BMI - Body Mass Index AUC - area under the curve CI - Confidence interval

FLUS - follicular lesion of undetermined significance

FN - Follicular neoplasm

SFN - suspicious for a follicular neoplasm

FNAC - fine-needle aspiration cytology

NCI - National Cancer Institute

OR - Odds ratio

ROC - receiver operator characteristics

TBSRTC - Bethesda System for Reporting Thyroid

Cytopathology

TNs - thyroid nodules

US - ultrasound

\section{Authors contributions}

All named authors played a substantial role in the conception and/or study design, data acquisition and/or analysis, as well as drafting of the manuscri agree the accountability for all aspects of accuracy and integrity of the work.

\section{Acknowledgments}

The authors thank Farhad Hosseinpanah for his help in the editing phase of the manuscript. Funding None.

\section{Conflict of Interest}

The authors declare they have no conflicts of interest.

\section{Ethical Publication Statement}

We confirm that we have read the Journal's position on issues involved in ethical publication and affirm that this report is consistent with those guidelines. 


\section{Corresponding Author}

Mehrzad Gholampour Dehaki, Department of Internal Medicine, School of Medicine, Aja University of Medical Sciences, Tehran, Iran. Tel:+989032721145

E-mail: mehr_ghol@yahoo.com

\section{E-mails of co-authors}

Mahdi Mohebbi:mohebbi1992@gmail.com Mahsa Mozaffari: mozaffari.m@tak.iums.ac.ir

\section{Reference}

1. Moon HJ, Kim EK, Yoon JH, Kwak JY. Malignancy risk stratification in thyroid nodules with nondiagnostic results at cytologic examination: combination of thyroid imaging reporting and data system and the Bethesda System. Radiology 2015;274:287-95.

2. Muratli A, Erdogan N, Sevim S, et al. Diagnostic efficacy and importance of fine-needle aspiration cytology of thyroid nodules. J Cytol 2014;31:73-8.

3. Jung CK, Baek JH. Recent Advances in Core Needle Biopsy for Thyroid Nodules. Endocrinol Metab (Seoul) 2017;32:407-12.

4. Jang EK, Song DE, Gong G, et al. Positive cytology findings and a negative histological diagnosis of papillary thyroid carcinoma in the thyroid: is it a false-positive cytology or a disappearing tumor? Eur Thyroid J 2013;2:203-10.

5. Liu X, Medici M, Kwong N, et al. Bethesda Categorization of Thyroid Nodule Cytology and Prediction of Thyroid Cancer Type and Prognosis. Thyroid 2016;26:256-61.

6. Handa U, Garg S, Mohan H, Nagarkar N. Role of fine needle aspiration cytology in diagnosis and management of thyroid lesions: A study on 434 patients. J Cytol 2008;25:13-7.

7. Ceratti S, Giannini P, Souza RAS, Rodrigues Jr OF. Ultrasound-guided fine-needle aspiration of thyroid nodules: assessment of theideal number of punctures. Radiol Bras 2012;45:145-8.

8. Cibas ES, Ali SZ. The Bethesda System for Reporting Thyroid Cytopathology. Thyroid 2009;19:1159-65.

9. Cibas ES, Ali SZ. The 2017 Bethesda System for Reporting Thyroid Cytopathology. Thyroid 2017;27:1341-6.

10. Reuters KB, Mamone MCOC, Ikejiri ES, et al. Bethesda Classification and Cytohistological Correlation of Thyroid Nodules in a Brazilian Thyroid Disease Center. Eur Thyroid J 2018;7:1338.

11. Auger M, Nayar R, Khalbuss WE, et al. Implementation of the Bethesda System for Reporting Thyroid Cytopathology: observations from the 2011 thyroid supplemental questionnaire of the College of American Pathologists. Arch Pathol Lab Med 2013;137:1555-9.
12. Kim M, Park HJ, Min HS, et al. The Use of the Bethesda System for Reporting Thyroid Cytopathology in Korea: A Nationwide Multicenter Survey by the Korean Society of Endocrine Pathologists. J Pathol Transl Med 2017;51:410-7.

13. Bongiovanni M, Papadakis GE, Rouiller N, et al. The Bethesda System for Reporting Thyroid Cytopathology Explained for Practitioners: Frequently Asked Questions. Thyroid 2018;28:55665.

14. Nabahati M, Moazezi Z, Fartookzadeh S, et al. The comparison of accuracy of ultrasonographic features versus ultrasound-guided fine-needle aspiration cytology in diagnosis of malignant thyroid nodules. J Ultrasound 2019 Apr 10. doi: 10.1007/s40477-019-00377-2. [Epub ahead of print].

15. Andrioli M, Carzaniga C, Persani L. Standardized ultrasound report for thyroid nodules: the endocrinologist's viewpoint. Eur Thyroid J 2013;2:37-48.

16. Pompili GG, Tresoldi S, Ravelli A, et al. Use of the ultrasound-based total malignancy score in the management of thyroid nodules. Ultrasonography 2018;37:315-22.

17. Gomez JS, Serrano LF. Use of the ultrasound-based total malignancy score in the management of thyroid nodules.Ultrasonography 2019;38:188-9.

18. Xie C, Cox P, Taylor N, LaPorte S. Ultrasonography of thyroid nodules: a pictorial review. Insights Imaging 2016;7:77-86.

19. Ram N, Hafeez S, Qamar S, et al. Diagnostic validity of ultrasonography in thyroid nodules. J Pak Med Assoc 2015;65:875-8.

20. Razmpa E, Ghanaati H, Naghibzadeh B, et al. Comparison of ultrasound findings with cytologic results in Thyroid nodules. Acta Med Iran. 2002:40:146-51.

21. Lin JD, Huang BY, Weng HF, et al. Thyroid ultrasonography with fine-needle aspiration cytology for the diagnosis of thyroid cancer. J Clin Ultrasound 1997;25:111-8.

22. Danese D, Sciacchitano S, Farsetti A. Diagnostic accuracy of conventional versus sonographyguided fine-needle aspiration biopsy of thyroid nodules. Thyroid 1998;8:15-21.

23. Nam-Goong IS, Kim HY, Gong $G$, et al. Ultrasonography-guided fine-needle aspiration of thyroid incidentaloma: correlation with pathological findings.Clin Endocrinol (Oxf) 2004;60:21-8.

24. Izquierdo R, Arekat MR, Knudson PE, et al. Comparison of palpation-guided versus ultrasoundguided fine-needle aspiration biopsies of thyroid nodules in an outpatient endocrinology practice. Endocr Pract 2006;12:609-14.

25. Frates MC, Benson CB, Doubilet PM, et al. Prevalence and distribution of carcinoma in patients 


\section{Thyroid nodules}

Eur J Transl Myol 29 (3): 261-267, 2019

with solitary and multiple thyroid nodules on sonography. J Clin Endocrinol Metab 2006;91:3411-7.

26. Ishida $\mathrm{T}$, Izuo $\mathrm{M}$, Ogawa $\mathrm{T}$, et al. Evaluation of mass screening for thyroid cancer. Jpn J Clin Oncol 1988;18:289-95.

27. Park NH, Kim DW, Park HJ, et al. Thyroid cysts treated with ethanol ablation can mimic malignancy during sonographic follow-up. J Clin Ultrasound 2011;39:441-6.

28. Alam T, Khattak YJ, Beg M, Raouf A, et al. Diagnostic accuracy of ultrasonography in differentiating benign and malignant thyroid nodules using fine needle aspiration cytology as the reference standard. Asian Pac J Cancer Prev 2014;15:10039-43.

29. Sankhla DK, Hussein SS, Bererhi H, et al. Are scintigraphy and ultrasonography necessary before fine-needle aspiration cytology for thyroid nodules? J Sci Res Med Sci 2001;3:29-33.

30. Papini E, Guglielmi R, Bianchini A, et al. Risk of malignancy in nonpalpable thyroid nodules: predictive value of ultrasound and color-Doppler features. J Clin Endocrinol Metab 2002;87:1941-6.

31. Kim EK, Park CS, Chung WY, et al. New sonographic criteria for recommending fine-needle aspiration biopsy of nonpalpable solid nodules of the thyroid. Am J Roentgenol 2002;178:687-91.

32. Xu T, Gu JY, Ye XH, et al.Thyroid nodule sizes influence the diagnostic performance of TIRADS and ultrasound patterns of 2015 ATA guidelines: a multicenter retrospective study. Sci Rep 2017;7:43183.

33. Kim H, Kim JA, Son EJ, Youk JH. Quantitative assessment of shear-wave ultrasound elastography in thyroid nodules: diagnostic performance for predicting malignancy. Eur Radiol 2013;23:2532-7

34. Park YJ, Kim JA, Son EJ, et al. Thyroid nodules with macrocalcification: sonographic findings predictive of malignancy.Yonsei Med J 2014;55:339-44.
35. Petrone L, Mannucci E, De Feo ML, et al. A simple ultrasound score for the identification of candidates to fine needle aspiration of thyroid nodules.J Endocrinol Invest 2012;35:720-4.

36. Koike E, Yamashita H, Noguchi S, et al. Effect of combining ultrasonography and ultrasound-guided fine-needle aspiration biopsy findings for the diagnosis of thyroid nodules Eur J Surg 2001;167:656-61.

37. Kwak JY, Han KH, Yoon JH, et al.Thyroid imaging reporting and data system for US features of nodules: a step in establishing better stratification of cancer risk. Radiology 2011;260(3):892-9.

38. Wang M, He X, Chang Y, et al. A sensitivity and specificity comparison of fine needle aspiration cytology and core needle biopsy in evaluation of suspicious breast lesions: A systematic review and meta-analysis. Breast 2017;31:157-66.

39. Moon WJ, Baek JH, Jung SL, et al. Ultrasonography and the ultrasound-based management of thyroid nodules: consensus statement and recommendations. Korean J Radiol 2011;12:1-14.

40. Ren J, Liu B, Zhang LL, et al. A taller-than-wide shape is a good predictor of papillary thyroid carcinoma in small solid nodules. J Ultrasound Med 2015;34:19-26.

41. Degirmenci B, Haktanir A, Albayrak R, et al. Sonographically guided fine-needle biopsy of thyroid nodules: the effects of nodule characteristics, sampling technique, and needle size on the adequacy of cytological material. Clin Radiol 2007;62:798-803.

42. Leenhardt L, Hejblum G, Franc B, et al. Indications and limits of ultrasound-guided cytology in the management of nonpalpable thyroid nodules. J Clin Endocrinol Metab 1999;84:24-8.

Submission: June, 23, 2019

Revision received: July 5, 2019

Acceptance: July 5, 2019 